\title{
Experimental and numerical investigations of oxide-related defects in Al alloy gravity die castings
}

\author{
Giulia Scampone $^{1} \cdot$ Raul Pirovano $^{2} \cdot$ Stefano Mascetti $^{2} \cdot$ Giulio Timelli $^{1}$ \\ Received: 28 February 2021 / Accepted: 8 July 2021 / Published online: 12 August 2021 \\ (C) The Author(s) 2021
}

\begin{abstract}
This research aimed to study the formation and distribution of oxide-related defects in the gravity die casting process of an AlSi7Cu0.5Mg alloy by using experimental and numerical investigations. Metallographic and image analysis techniques were conducted to map the distribution of oxide inclusions inside the casting at the microscopic level. Numerical simulations were used to analyse the filling and solidification stages, and to foresee the turbulence of the melt and the formation of the oxide defects. The results show that most of the defects were correlated with the oxide layers or bubbles entrained inside the liquid metal. The accuracy of the numerical code in simulating the metal fluid-dynamic behaviour and the heat transfer was verified, and the results were in agreement with the experimental findings. The numerical distribution of defects was consistent with the experimental results, proving that the model successfully predicted the formation of oxide-related defects.
\end{abstract}

Keywords Aluminium alloys $\cdot$ Filling $\cdot$ Entrainment $\cdot$ Double oxide defects $\cdot$ Microstructure $\cdot$ Numerical simulation

\section{Introduction}

The final performances of aluminium (Al) alloy castings are strongly affected by the manufacturing process [1]. To produce high-integrity components, the casting temperatures, pressures, times, filling velocity and molten metal quality must be carefully controlled [2-4].

The preparation of the molten metal and the pouring and filling phases are among the most critical stages of the casting process. When liquid $\mathrm{Al}$ is exposed to the atmosphere, it immediately forms an oxide layer on the metal surface $[5,6]$. If

Giulia Scampone

giulia.scampone@phd.unipd.it

Raul Pirovano

raul.pirovano@xceng.com

Stefano Mascetti

stefano.mascetti@xceng.com

Giulio Timelli

timelli@gest.unipd.it

1 Department of Management and Engineering, University of Padova, Stradella S. Nicola, 3, 36100 Vicenza, Italy

2 XC Engineering Srl, Via Giacomo Matteotti, 7, 22063 Cantù, Italy the flow regime is turbulent, the oxide surface can fold back on itself and be entrapped inside the bulk liquid. This generates an entrainment defect known as bifilm [5, 7]. Campbell [5] demonstrated how the great majority of scrap castings acquire that status during the first few seconds of the pouring phase. At this stage, bifilms are easily entrapped inside the casting, promoting the formation of several casting defects, such as gas and shrinkage porosity and hot tearing [7-10]. Theoretically, a casting free from bifilms would be sound and free from any casting defects $[7,11]$.

The decrease in the mechanical properties due to the presence of double oxide defects is well known [12-14], and it affects the components produced by gravity casting [15] and low-pressure casting $[16,17]$. An accurate preparation of the melt with degassing and filter systems is effective for preventing the entrainment of thick bifilms (thickness $=$ $10 \mu \mathrm{m} \div 1 \mathrm{~mm}$ ) inside the casting [8, 12, 18]. In contrast, thinner bifilms, generated by the action of turbulence during the pouring and filling phases, are difficult to eliminate, due to their small size (thickness $=1 \mathrm{~nm} \div 1 \mu \mathrm{m}$ ) [5]. Therefore, numerical simulations that can predict the formation and entrapment of double oxide films may improve the casting design and allow a more effective setup of the casting process parameters. In [19], a detailed review of the numerical methods used to model the entrainment of air and oxide surface during the casting process has been reported. 
Currently, many aspects of bifilms have been studied in detail. Yue et al. investigated the evolution of these defects in the liquid state and during the solidification [20], while Tiryakioglu et al. [3] analysed the influence of the filling velocity on their formation. A three-dimensional reconstruction of a bifilm morphology and the variation of its chemical composition with the thickness have been reported in [21], while the effects of holding time and alloying elements, such as Mo and $\mathrm{Sr}$, on the formation of double oxide films have been studied in $[8,22]$. Moreover, many papers in the literature have characterised double oxide defects on the fracture surface and have investigated their impact on the mechanical properties $[8,14,16]$ or have correlated the numerical results with the experimental data related to the formation of macroporosities or superficial defects [21, 23-25]. However, to the best of the authors' knowledge, few studies have been conducted to map and analyse the experimental distribution of oxide-related defects at the microscopic level.

This work aims to compensate for this gap of knowledge by examining the formation of bifilms using experimental and numerical investigations. The analysis of the filling phase is intended to describe the fluid motions involved in the generation of oxide films and to verify the numerical accuracy of the fluid-dynamic model. Furthermore, an experimental mapping of oxide-related defects is carried out to provide the data necessary to validate the numerical models concerning the bifilms' entrainment.

\section{Theoretical background}

The complex morphology and the reduced size of double oxide defects make their quantification and analysis a non-trivial task. Although many techniques, e.g. the reduced pressure test, the liquid metal cleanness analyser, PODFA and PREFIL tests, are practical tools for evaluating the initial molten metal quality before casting, the presence and distribution of bifilms throughout solid castings are more difficult to detect and quantify [5]. Double oxide defects are often too small to be detected by conventional X-ray investigations, and they are mainly investigated by destructive metallographic techniques, e.g. optical or scanning electron microscopy $[10,12,14,22$, 26]. Recently, the spread of computer tomography and ultrafast synchrotron-based X-ray tomographic microscopy has allowed reconstructing the morphology of entrainment defects and investigating their evolution during solidification [20,21].

These experimental techniques are mainly used to locally characterise bifilms, while a global view of the distribution of entrainment defects inside cast components is generally achieved by using numerical simulations.

Either indiscrete or discrete methods could be implemented in computational fluid dynamics (CFD) codes to predict the entrainment of air and oxide surfaces during casting processes. In indiscrete models, the magnitude of the entrained oxides can be assessed quantitatively and qualitatively, but the location of each defect is unknown. In contrast, the discrete models identify the entrainment mechanisms and the final defect location, but they are often computationally less efficient [19]. In these methods, the free surface, i.e. the interface between gas and liquid phases, must be accurately tracked to determine the position and the growth time of the oxide film.

One of the most diffused approach to model the formation of oxide defects is the cumulative scalar technique [19, 27]. According to this indiscrete approach, the oxide defects are accumulated at a constant rate on the free surface and a scalar parameter describes this accumulation. Casting regions with higher scalar values may present a higher number of oxide defects [27]. The drawbacks of this technique are related to its inability to model the strength effect and the buoyancy of the bifilm, as well as its adhesion to the mould's walls. Moreover, the scalar value can diffuse throughout the fluid metal under the action of weak fluctuations of the fluid, while the oxide layer can be only entrained inside the bulk liquid under the action of turbulent motion. As stated by Barkhudarov and Hirt [27], it is impossible to assign any significance to the absolute values of the scalar parameter without detailed experimental comparisons to correlate the model predictions with the real casting defects.

\section{Experimental procedure}

\subsection{Alloy and casting parameters}

A primary AlSi7Cu0.5Mg cast alloy (EN AC-45500 [28]) in the form of ingots and a permanent steel mould, designed according to CEN/TR 16748:2014 standards [29], were selected for the casting trials. The chemical composition of the alloy is shown in Table 1.

The die, illustrated in Fig. 1, was made of AISI H11 tool steel, and it enabled to cast a cylindrical-shaped bar with a total length and mean diameter of $190 \mathrm{~mm}$ and $15 \mathrm{~mm}$, respectively (Fig. 2). Before the casting trials, a semi-permanent layer of Foseco Dycote ${ }^{\circledR}$ F34 coating [30] was sprayed over the die walls at a temperature of about $200^{\circ} \mathrm{C}$, according to standard foundry practise. To ensure the good reproducibility of the tests

Table 1 Chemical composition (wt.\%) of the experimental AlSi7Cu0.5Mg alloy

\begin{tabular}{llllllllll}
\hline $\mathrm{Si}$ & $\mathrm{Fe}$ & $\mathrm{Cu}$ & $\mathrm{Mn}$ & $\mathrm{Mg}$ & $\mathrm{Ni}$ & $\mathrm{Zn}$ & $\mathrm{Cr}$ & $\mathrm{Ti}$ & $\mathrm{Al}$ \\
\hline 6.50 & 0.089 & 0.652 & 0.012 & 0.431 & 0.005 & 0.004 & 0.014 & 0.121 & bal.
\end{tabular}



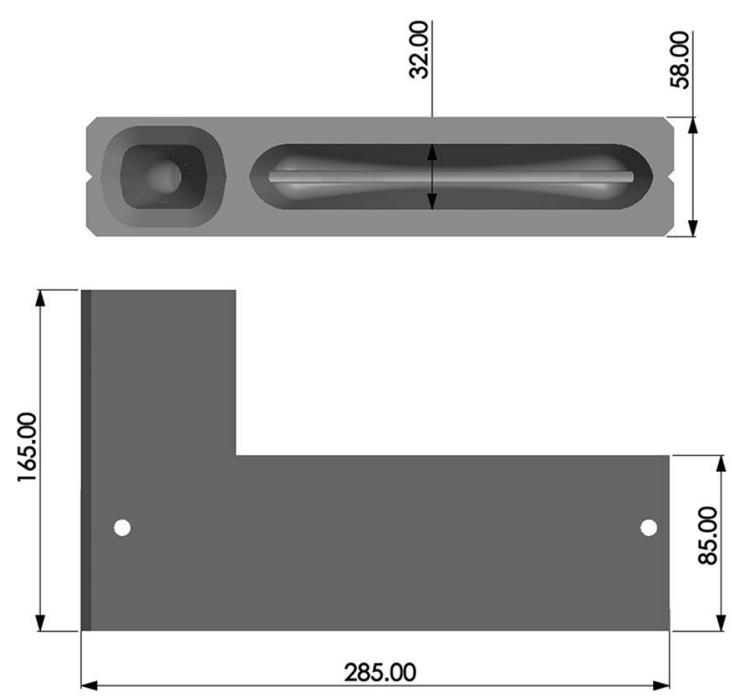

Fig. 1 Design of the permanent mould with overall dimensions (in $\mathrm{mm}$ )

and monitoring the variation of the mould temperature during the trials, a K-type thermocouple (Ø1 $\mathrm{mm}$ ) was embedded into the die, and it was located in the middle of the cylindricalshaped bar, $2 \mathrm{~mm}$ from the surface of the cavity.

The AlSi $7 \mathrm{Cu} 0.5 \mathrm{Mg}$ cast alloy was melted at $780 \pm 5^{\circ} \mathrm{C}$ into a silicon carbide $(\mathrm{SiC})$ crucible in an electric resistance furnace. After melting, the temperature of the bath was decreased to $750 \pm 5^{\circ} \mathrm{C}$ for the degassing phase. To increase the quality of the molten metal and to remove impurities and old oxides, the bath was degassed with argon for 30 min and accurately skimmed with a coated paddle. This procedure ensured that the defects detected in the final castings were primarily correlated to the presence of young bifilms that were generated during the pouring and filling phases.

Afterwards, the temperature of the molten metal was further decreased to $725 \pm 5^{\circ} \mathrm{C}$ and the die was homogeneously pre-heated at $400 \pm 3^{\circ} \mathrm{C}$ in an electric resistance muffle furnace.

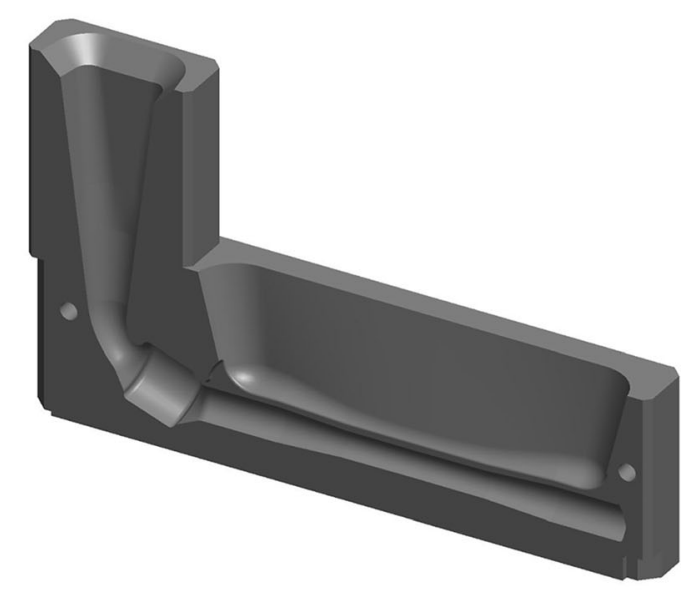

The melt was manually poured in $3 \mathrm{~s}$ at $725 \pm 5^{\circ} \mathrm{C}$, causing the die temperature to increase from $400 \pm 3^{\circ} \mathrm{C}$ to $450 \pm 2^{\circ} \mathrm{C}$. The flow path of the molten metal was captured through the aperture of the riser using a high-speed camera with a sampling rate of 240 frames per second and a shutter speed of 1/8000 s.

A batch of 10 castings was produced, taking care to gently stir and manually skim the molten metal before any casting. Filtering operations, as well as chemical eutectic modification or grain refinement, were not performed in the present work. The selected casting parameters and the absence of the filter promoted high surface turbulence during the filling stage and induced the formation of entrainment defects inside the castings.

\subsection{Metallographic characterisation}

For the metallographic investigations, samples were drawn from the cross-section of the castings as shown in Fig. 2. The samples were mechanically prepared to a $3-\mu \mathrm{m}$ finish
Fig. 2 Geometry of the casting used to produce separatelypoured cylindrical-shaped bars (dimensions in $\mathrm{mm}$ ); the cutting planes (A-A and B-B) to draw the specimens for metallographic investigations are also indicated

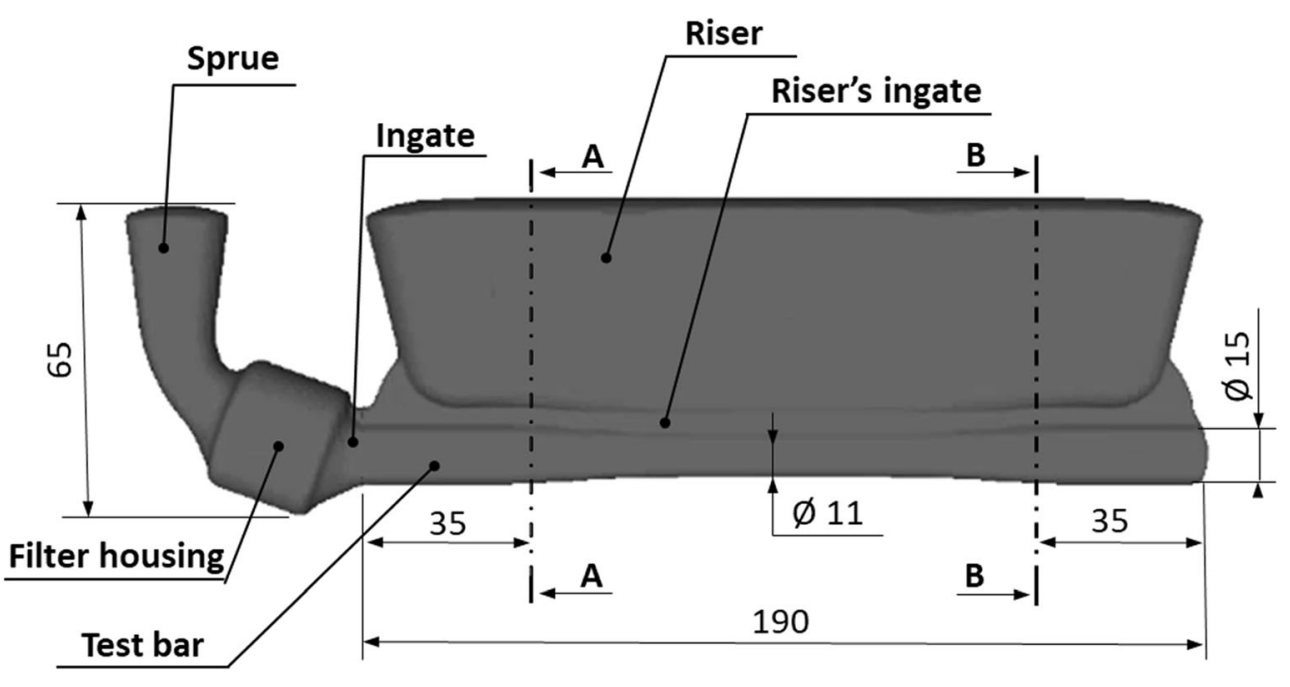


with diamond paste and, finally, polished with a commercial $0.04-\mu \mathrm{m}$ silica colloidal suspension. The polished specimens were then etched in a solution of $5 \mathrm{vol} \% \mathrm{HF}$ and $95 \mathrm{vol} \% \mathrm{H}_{2} \mathrm{O}$ to better evidence the entrained oxide inclusions [31].

Microstructural observations were carried out using an optical microscope (Leica ${ }^{\circledR}$ DMLA) and a field emission gun scanning electron microscope (FEG-SEM, FEI ${ }^{\circledR}$ QUANTA 250) equipped with an energy-dispersive spectrometer (EDS, EDAX®). To quantify the microstructural features, the optical micrographs were processed using image analysis software, which was focused on the secondary dendrite arm spacing (SDAS) measured by applying the line intercept method [32].

The oxide-related defects were mapped throughout the entire cross-sections indicated in Fig. 2 by exploiting the automatic handling of the microscope stage. Contiguous micrographs, each with an area of $1.2 \times 0.9 \mathrm{~mm}^{2}$, were automatically collected throughout the whole section. The severity of the entrained oxide inclusions was evaluated for each field based on the reference micrographs, as shown in Fig. 3. Five severity grades (SGs) were defined according to the area of defects, which was quantitatively analysed using the image analyser. The total measured defect area in the micrograph was then divided by the initial area of the micrograph to determine the area fraction covered by the oxide-related defects $\left(A_{D}\right)$. As shown in Fig. 3, each SG was associated with a different colour and a range of $A_{D}$ values. The $A_{D}$ ranges were selected to emphasise the low damage conditions. In general, a region containing few closed bifilms or porosity, referring to gas precipitation within a bifilm, with a maximum size of about $20 \mu \mathrm{m}$ was categorised as grade 1 . Regions showing coarser unfurled bifilms and porosity with a maximum size of $300 \mu \mathrm{m}$ were categorised as grade 4 .

The result of mapping the oxide-related defects throughout a cross-section is shown in Fig. 4a. Furthermore, the distribution of the oxide-related defects, representative of the experimental conditions, was obtained as a statistical average of the sections drawn from five different castings, as shown in the coloured map in Fig. 4b.

To analyse the distribution of the entrained oxide inclusions, a convolutional neural network (CNN) technique was applied. CNN is a deep learning algorithm designed for image analysis; it is based on the convolution and pooling operations at the pixel level. The convolution operation was used to extract a feature map from the image by using multiple filters (kernels), while the pooling operation, also called subsampling, permitted the reduction of the dimensionality of the feature map and, therefore, the local sensibility of the image [33].

A typical $2 \times 2$ kernel was defined with a stride length equal to 2 , that is, the filter moved two pixels on the input image at one time. Groups of four $(2 \times 2)$ contiguous micrographs were generated, representing a surface area of about $4.3 \mathrm{~mm}^{2}(2.4 \mathrm{~mm} \times 1.8 \mathrm{~mm})$. Therefore, an average pooling operation was carried out where the SG assigned to each kernel was equal to the average value of the micrographs' group, as shown in Fig. 4c. This procedure resulted in a lower resolution version of the
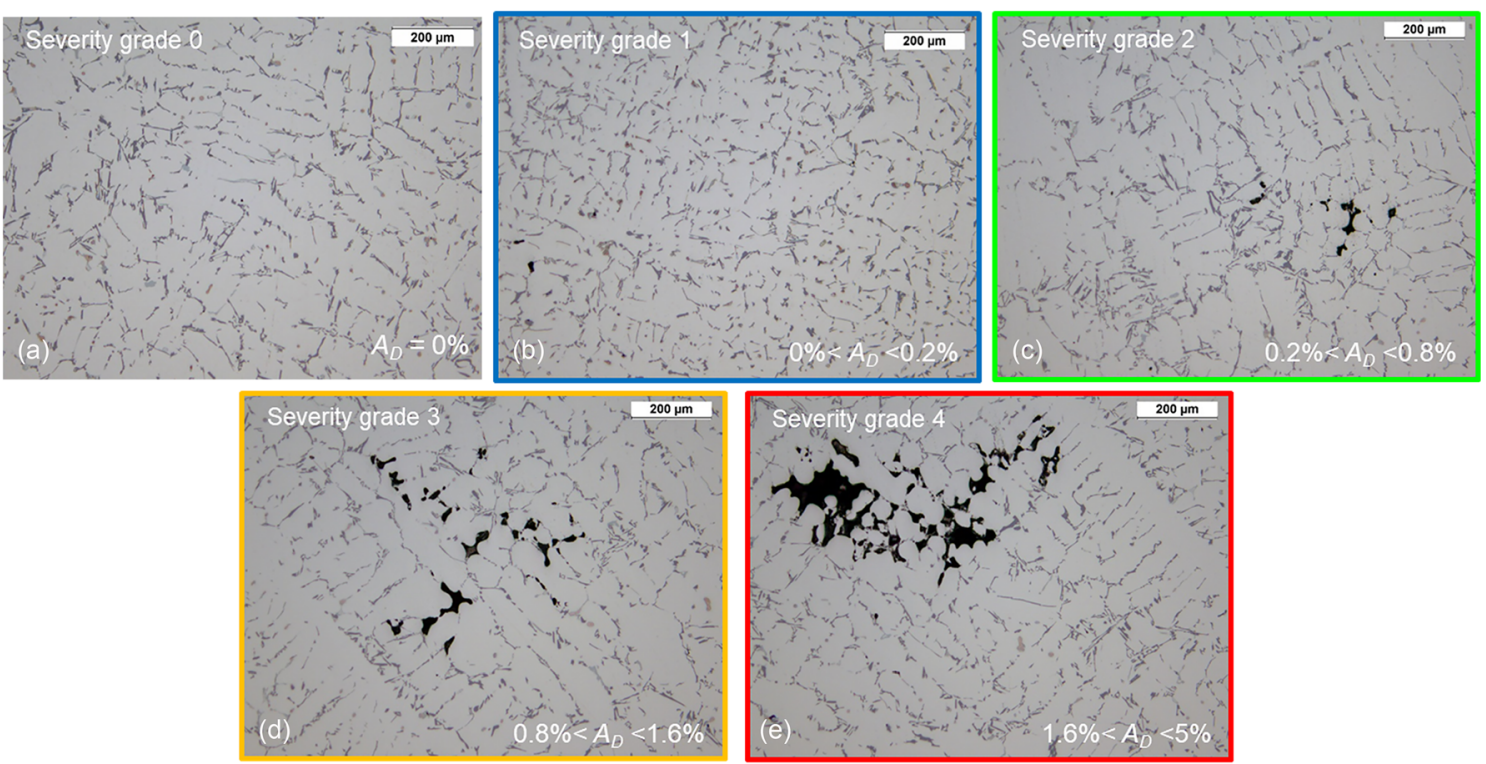

Fig. 3 Reference micrographs used to evaluate the severity grade (SG) of the oxide-related defects: a SG 0, b SG 1, c SG 2, d SG 3 and e SG 4. Different coloured contours mark the reference micrographs (colour

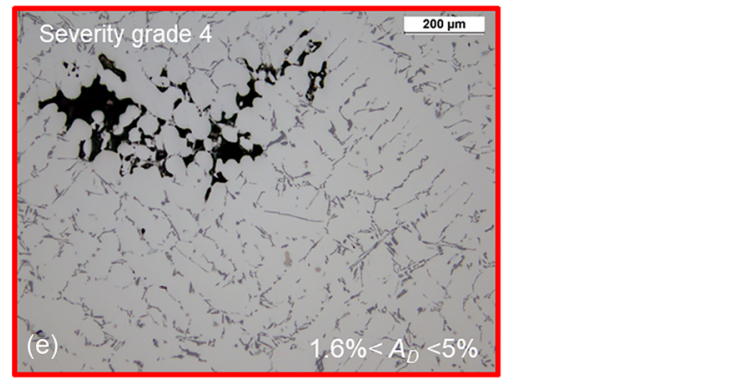

figures online). The typical area fractions covered by the oxide-related defects $\left(A_{D}\right)$ are also indicated as an inset 


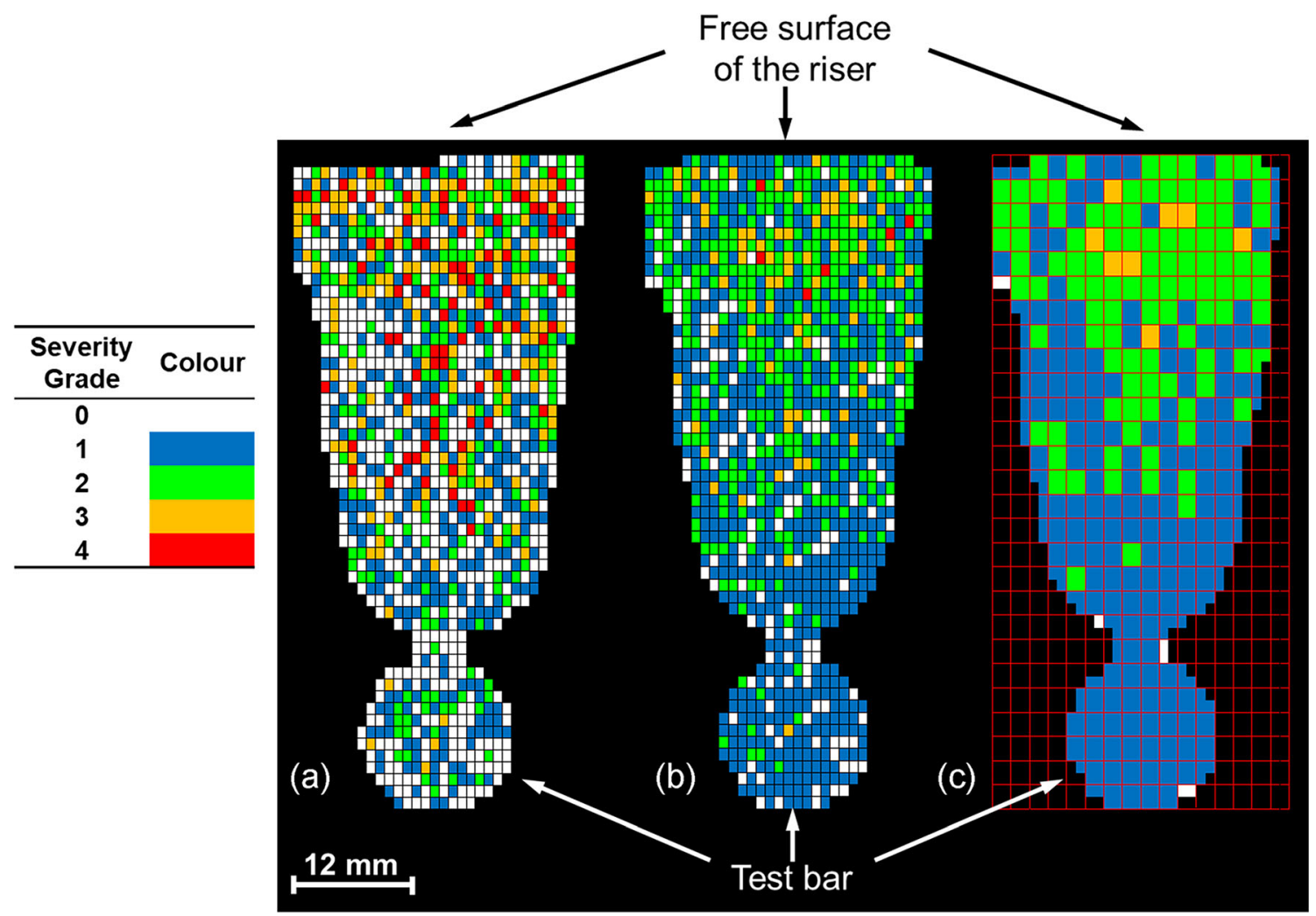

Fig. 4 a Typical coloured mapping of the oxide-related defects throughout a cross-section of the casting and $\mathbf{b}$ an example of a representative condition of the experimental case, obtained as the statistical average in different castings. In both images, each pixel corresponds to an

mapping, which still contained the important structural elements without the unnecessary fine details.

\section{Simulation methodology}

\subsection{Model formulation}

In the present work, the numerical analysis was performed using FLOW-3D, which is a CFD code based on the finite volume discretization method [34]. This code uses the Fractional Area-Volume Obstacle Representation (FAVOR) methodology to model geometries, and the volume of fluid (VOF) method to track the free surfaces. Detailed descriptions of these algorithms can be found in [35, 36].

A cumulative scalar technique existing in the commercial software was used to predict the formation of entrainment defects [27]. At each time step, the concentration of the oxides $\left(O_{x}\right)$ accumulated in a cell of the mesh is provided according to the following equation:

$$
O_{x}=\operatorname{DFTSRF} \cdot F_{s} \cdot t
$$

where $F_{s}$ is the metal surface area in contact with the atmosphere, $t$ is the exposure time and DFTSRF is the calibration investigated area of $1.2 \times 0.9 \mathrm{~mm}^{2}$. c Experimental distribution of the oxide-related defects after the application of the CNN method where $2 \times 2$ kernels are contoured in red. The severity grade, as defined in Fig. 2, is reported in the legend (colour figures online)

coefficient that considers the chemical composition of the alloy and the specific weight of the oxide.

Fluid fluctuations or convective motions can change the value of the oxide concentration accumulated in a cell of the mesh. When these conditions are present, a transport equation is numerically solved using a second order scheme that preserves monotonicity; in this way, a scalar value can diffuse from a cell to adjacent ones. The diffusion rate is controlled by a molecular diffusion coefficient, which is a function of the dynamic viscosity and density of the fluid [34]. This surface defects model allows for predicting the distribution of casting defects due to surface turbulence.

\subsection{Simulation of the gravity die casting process}

FLOW-3D CAST v5.1 (2020) commercial software [34], with its workspace for gravity die casting, was used to simulate the filling and solidification phases of the casting process. The three-dimensional (3D) computer-aided design model of the die was drawn and imported into the simulation software. The physical properties of the die were defined as a linear function of the temperature in the working temperature range of 400 $450^{\circ} \mathrm{C}$. The thermal conductivity varied from 34.2 to 33.4 
$\mathrm{W} /(\mathrm{m} \cdot \mathrm{K})$, while the specific heat was included in the range $620-650 \mathrm{~J} /(\mathrm{kg} \cdot \mathrm{K})$.

The properties of the alloy were set as a function of the temperature ranging from 25 to $750^{\circ} \mathrm{C}$. The solidus and liquidus temperatures were imposed at $540^{\circ} \mathrm{C}$ and $616^{\circ} \mathrm{C}$, respectively. The density ranged from 2690 to $2410 \mathrm{~kg} / \mathrm{m}^{3}$, the thermal conductivity was included between 176 and $85 \mathrm{~W} /(\mathrm{m}$. $\mathrm{K})$, while the specific heat varied from 886 to $1160 \mathrm{~J} /(\mathrm{kg} \cdot \mathrm{K})$.

The interfacial heat transfer coefficient (IHTC) was approximated by two constant values for completely liquid and solid states, while it followed a linear variation between these two values during the phase transition interval. In particular, the IHTC value was set equal to $2700 \mathrm{~W} /\left(\mathrm{m}^{2} \cdot \mathrm{K}\right)$ and 1000 $\mathrm{W} /\left(\mathrm{m}^{2} \cdot \mathrm{K}\right)$ above the liquidus and below the solidus temperatures, respectively. The IHTC controls the heat exchange at the metal-mould interface, and especially due to the progressive formation of an air gap between the die wall and the casting part, its value decreases during the solidification stage. Different models of IHTC are used during the casting simulation, e.g. the approximation with a constant value, the linear or exponential correlation with the casting temperature at the interface, the empirical Lewis-Ransing correlation [37, 38]. The model used in the present work is well known and diffused in numerical casting simulation because it provides a good compromise between reliable results and reduced calculation time.

To increase the reliability of the numerical simulation, the process parameters used during the experimental procedure were imported. Therefore, the pouring and die temperatures were $730^{\circ} \mathrm{C}$ and $400^{\circ} \mathrm{C}$, respectively. The flow rate was set constant at $9.1 \cdot 10^{-5} \mathrm{~m}^{3} / \mathrm{s}$ in the first $2.6 \mathrm{~s}$, and then it progressively decreased in the remaining filling time $(0.4 \mathrm{~s})$.

The following models were used during the casting simulation:

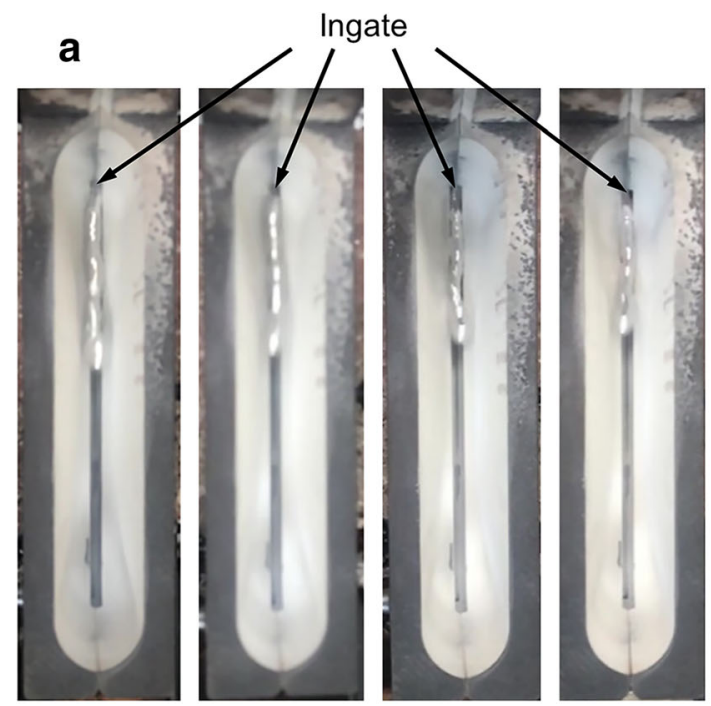

- The gravity model was applied to evaluate in detail the gravity effect on the flow motion.

- The adiabatic gas regions model was enabled to control the behaviour of the gas bubbles inside the liquid metal; this model allowed neither energy exchange nor mass transfer between a bubble and the surrounding environment. Inside each region of gas, the pressure and the temperature were uniform and varied with the volume [39].

- The $k$ - $\omega$ turbulence model, a two-equation model, was used as an approximation of the Reynolds-averaged Navier-Stokes equations to represent the turbulent properties of the flow [40].

- The surface tension model was enabled to predict the surface tension forces, in particular, the adhesion forces gripping the solid surfaces [41].

Virtual vents were located along the parting line of the die to model the leakage of air.

A mesh of 870,000 cubic cells with a uniform grid size of $1.25 \mathrm{~mm}$ was automatically generated by the software for the whole system (die and casting); a mesh of 330,400 cubic cells was made for the die cavity.

The free surface defects concentration was the software output used to analyse the numerical distribution of oxide inclusions. The model was previously described in Section 2.

\section{Results}

\subsection{Repeatability of the filling phase}

To ensure the reliability of the experimental results, the repeatability of the casting process was first evaluated. The frames,

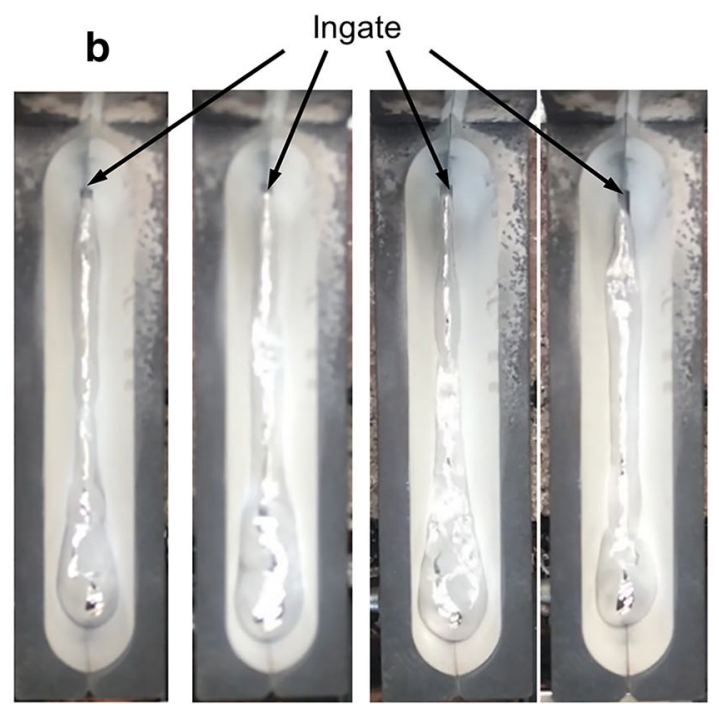

Fig. 5 Metal flow at a $0.24 \mathrm{~s}$ and $\mathbf{b} 0.50 \mathrm{~s}$ from the beginning of the pouring phase during four different experimental trials 
captured during the casting trials, were analysed to evaluate the filling phase in the different tests.

Figure 5 shows the images at $0.24 \mathrm{~s}$ and $0.50 \mathrm{~s}$ from the beginning of the pouring phase. While Fig. 5a illustrates the initial metal flow inside the cavity of the test bar, the frames in Fig. $5 \mathrm{~b}$ refer to the initial filling of the riser, which seems to begin in the zone that is furthest from the ingate.

In general, a good correspondence in the metal position and the die filling level appears evident, highlighting a similar fluid-dynamic behaviour in the different experimental tests. This consistency in the empirical results assures the validity of the collected data.

\subsection{Fluid-dynamic analysis of the die filling}

The accuracy of the numerical code to simulate the fluiddynamic behaviour of the liquid metal was verified by comparing the flow path between the actual experiment and the numerical solution. Figure 6 shows the comparison between the numerical simulation result (right) and the flow visualisation experiment (left) through the open-type riser; the flow pattern inside the die cavity refers to different times from the beginning of the pouring phase.

Figure 6a shows the flowing metal inside the cavity of the test bar at $0.20 \mathrm{~s}$ from the beginning of the casting. The numerical prediction was in agreement with the experimental findings; the position of the fluid front, as well as the fluid path inside the die cavity, was comparable.

The liquid metal flowed along the cavity of the test bar and struck the far side of the die cavity, generating a returning wave (Fig. 6b). The flow front folded over itself and flowed back towards the ingate. This folding mechanism results in the formation of a bifilm, where the two sides of the solid oxide film can entrap a small volume of air/gas between them while surrounded by the liquid melt.

At $0.42 \mathrm{~s}$ from the beginning of the pouring, the liquid metal started to fill the region of the riser where two different fluid fronts flowing in opposite directions were generated (Fig. 7). The first front was given by the metal that rose from the middle zone of the passage linking the riser to the cavity of
Fig. 6 Comparison of the numerical simulation result (right) and the flow visualisation experiment (left) through the open-type riser; the time shown in $\mathbf{a}-\mathbf{f}$ is the actual experimental time from the beginning of the pouring phase
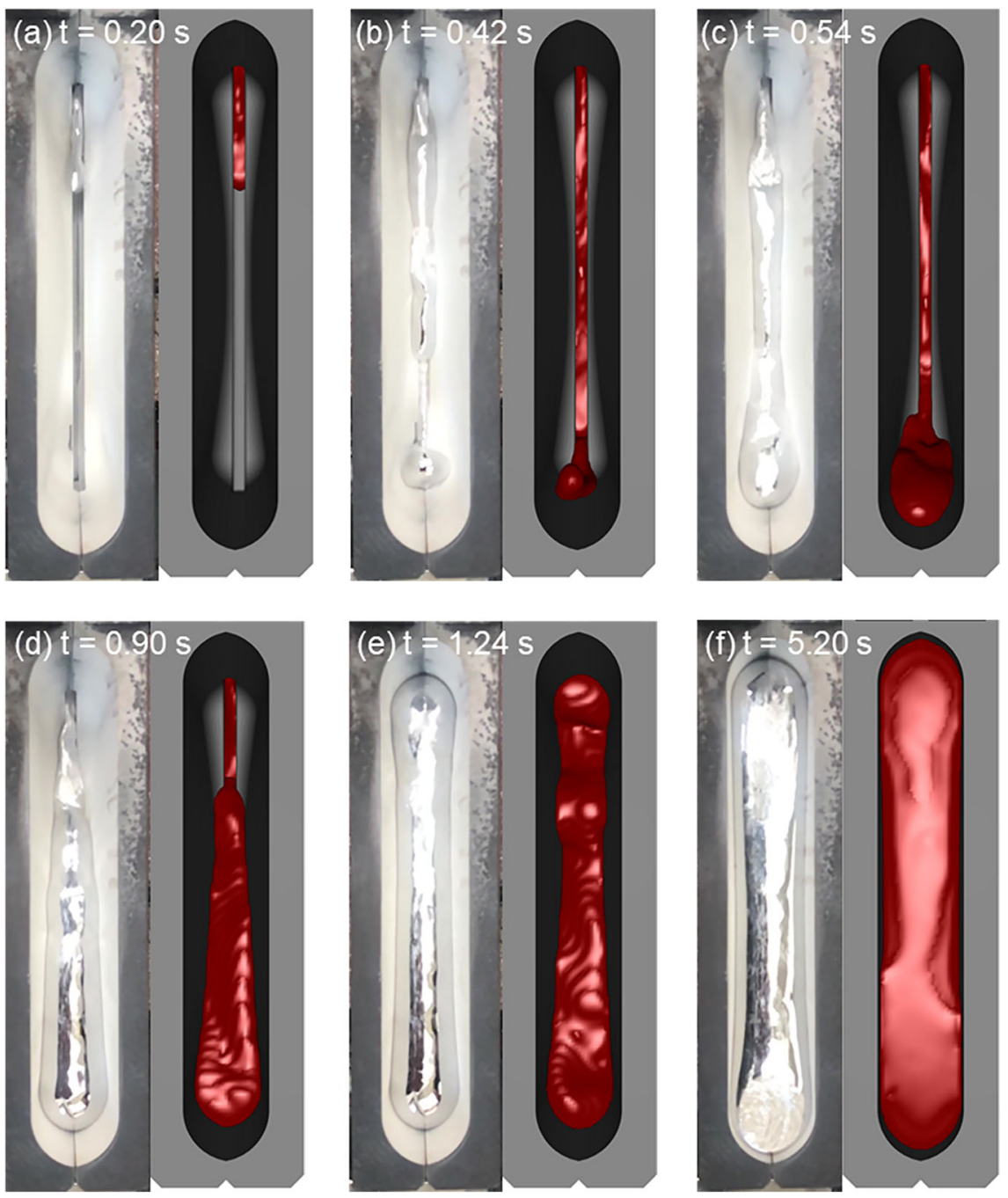

$30 \mathrm{~mm}$ 
Fig. 7 Beginning of the riser filling; two different flow fronts contoured by dashed lines rose from the riser's ingate and flowed in opposite directions, as indicated by the arrows

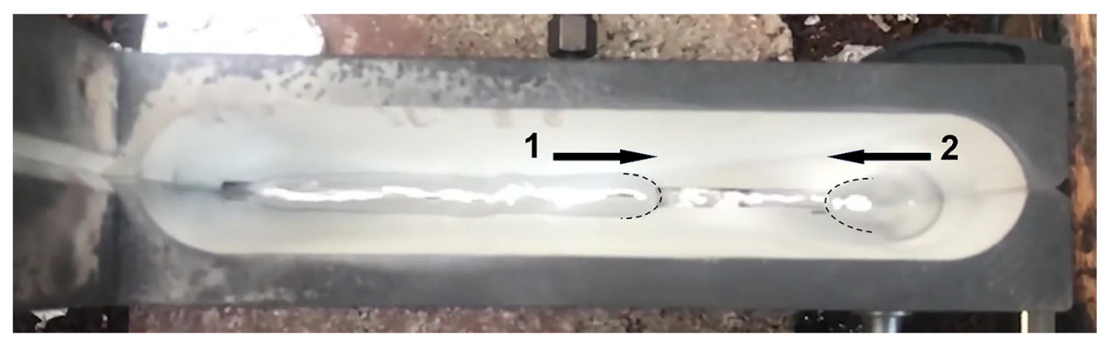

the test bar, then flowing towards the distant side of the die cavity (indicated as \#1 in Fig. 7). The other flow front was the returning wave that was previously mentioned (indicated as \#2 in Fig. 7). When the two fronts meet and join each other, the oxide skin covering the surface of the liquid can be partially entrained inside the bulk liquid, thereby promoting the formation of the oxide-related defects.

The die filling proceeded with the accumulation of liquid $\mathrm{Al}$ in the zone of the riser far from the ingate, visible in both the simulated and experimental results at $0.54 \mathrm{~s}$ and $0.90 \mathrm{~s}$ (Fig. 6c, d), respectively. From $1.24 \mathrm{~s}$, the action of the unzipping waves completed the filling phase (Fig. 6e). The molten metal flowed under the surface skin, gradually increasing the level of liquid inside the die cavity. This filling mode mitigated the entrapment of bifilms because the surface film was not very perturbated.

As seen in Fig. 6e, f, some differences appear in the flow path between the actual experiment and the numerical results. While the fluid ripples were numerically evident, during the experimental tests they could only be slightly observed below the oxidised surface. This difference was related to the difficulty of the numerical code in modelling the surface oxide skin, which hid the fluctuations of the liquid metal. At $5.20 \mathrm{~s}$ (Fig. 6f), although the die cavity was completely filled, the fluid was not at rest: flow fluctuations could still be detected, especially inside the riser. These movements are clearly visible in the numerical results seen in Fig. 6f, and they gradually weakened over time until they stopped completely $25 \mathrm{~s}$ after the beginning of the pouring phase.

\subsection{Solidification analysis}

Even though oxide-related defects are primarily formed during the filling phase, their final distribution inside the casting is also influenced by the solidification stage. A premature or delayed solidification of the material affects the flow motions that are responsible for the redistribution of the defects. To increase the reliability of the numerical simulation, the simulated heat transfer has to be consistent with the empirical one. Thus, the solidification behaviour of the casting was studied to evaluate the reliability of the thermal parameters set in the numerical simulation and to ensure reliable modelling of the heat exchange. In particular, the correspondence between the experimental and numerical cooling rates was evaluated.
In the present work, the mean cooling rate $(\mathrm{R})$ was estimated according to the empirical relation

SDAS $=39.4 \cdot \mathrm{R}^{-0.317}$ proposed by Wang et al. [42] for AlSi foundry alloys, where SDAS represents the scale of the primary $\alpha$-Al phase. In the central area of the test bar of both the investigated sections, the average value of SDAS was equal to $27 \pm 3 \mu \mathrm{m}$, corresponding to a cooling rate of approximately $3.3^{\circ} \mathrm{C} / \mathrm{s}$.

To assess the simulated cooling rate, a region of interest was defined in correspondence of the gauge length, and the variations in the cooling rate were plotted as a function of time. The mean cooling rate of the primary $\alpha$ - $\mathrm{Al}$ dendrites during solidification was equal to $3.3^{\circ} \mathrm{C} / \mathrm{s}$, which is in agreement with the experimental data. This could also ensure the reliability of the thermal parameters set in the numerical simulation and the accuracy in the heat exchange modelling. Figure 8 illustrates the numerical distribution of the cooling rate in the section next to the ingate (A-A) at the dendritic coherence point, when the solid fraction was approximately equal to 0.18 , and the temperature was about $608^{\circ} \mathrm{C}$ [43].

The cooling rate decreased with the distance from the die walls and the thickness of the casting. It ranged from about $0.8^{\circ} \mathrm{C} / \mathrm{s}$ in the upper central zone of the riser to a maximum value of about $10^{\circ} \mathrm{C} / \mathrm{s}$ in some areas of the test bar that were in contact with the die surface. In the central region of the test bar, the cooling rate ranged between 2.5 and $5^{\circ} \mathrm{C} / \mathrm{s}$, with an average value of about $3.3^{\circ} \mathrm{C} / \mathrm{s}$. The same distribution of

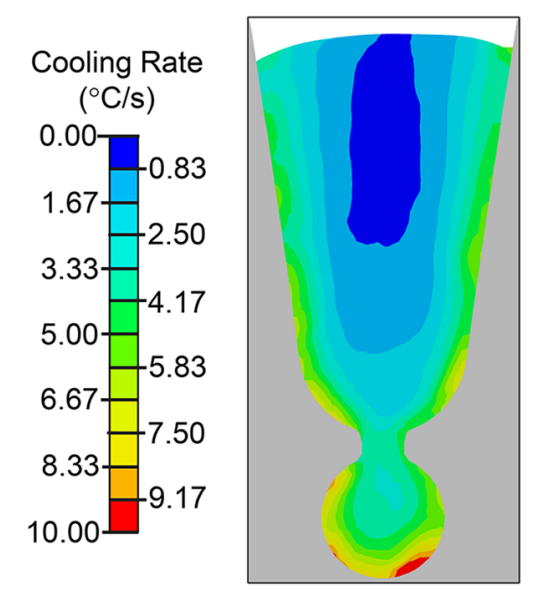

Fig. 8 Distribution of the calculated cooling rate throughout the investigated A-A cross-section in the $\mathrm{Al}$ alloy casting (colour figure online) 
cooling rate was detected in section B-B, which was about $155 \mathrm{~mm}$ from the ingate.

\subsection{Microstructural and oxide-related defects investigation}

The casting defects generated by entrainment of the bifilms were the typical casting defects detected throughout the microstructure, as shown in Fig. 9. Both large and small porosities were contoured by a thin oxide layer (Fig. 10a), as revealed by the EDS analyses (Fig. 10b, c). High levels of oxygen were identified in correspondence of the film, consistent with oxide entrapment [7]. Furthermore, the reduced thickness of the film, here observed typically in the range of 0.1 to 0.6 $\mu \mathrm{m}$, demonstrates that its formation began in the pouring or filling stages. No thick oxides (i.e. old oxides) were observed, indicating the high efficiency of preliminary degassing used in the present work.

The presence of thin oxide layers contouring porosities suggested that they acted as formation points for the growth of solidification defects (see Fig. 9). The unbounded oxide surfaces of a bifilm can be easily separated with minimal gas pressure or minimal stress, forming pores or cracks. In contrast, the nucleation of volume defects, as an atomic-sized event, is extremely difficult due to the perfect atomic contact and the strength of the boundaries [7].

Figure 11 shows the distribution of the SGs related to the casting defects generated by the entrainment of bifilms in two different cross-sections of the castings after application of the CNN method. Section A-A was located close to the ingate (35 $\mathrm{mm}$ ), while section B-B was about $155 \mathrm{~mm}$ from the ingate.

In both sections, the area fraction covered by the oxiderelated defects increased from the region of the test bar

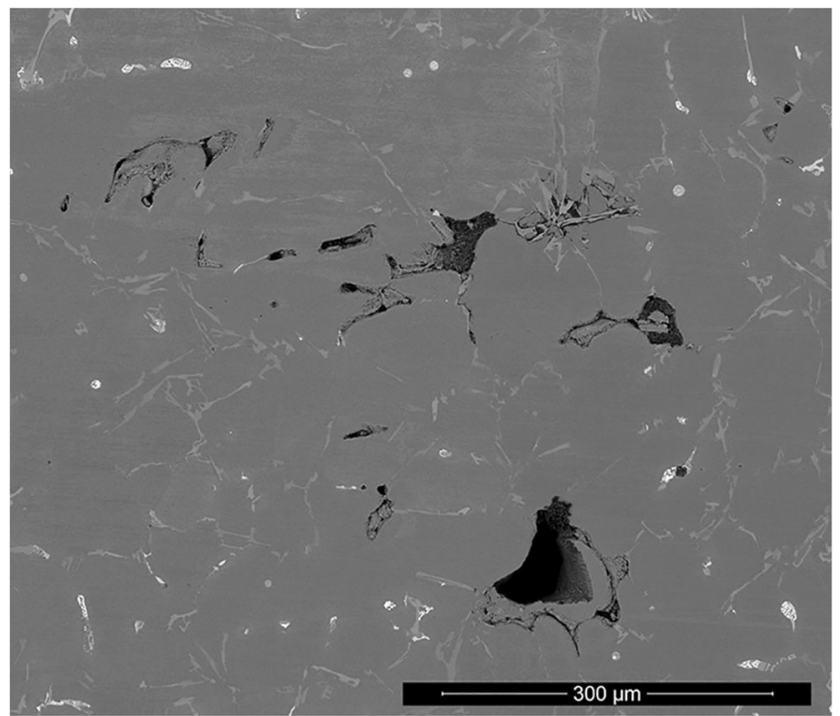

Fig. 9 FEG-SEM micrograph showing typical casting defects generated by the entrainment of bifilms in the experimental $\mathrm{Al}$ alloy castings towards the free surface of the riser. In particular, the average SG value in the tensile test sample was less than 1 , and it gradually increased up to local values of about 3 in the upper part of the riser. The main difference detected between the two sections was seen in the lower zone of the riser. Slightly higher values of $A_{D}$, which means more oxide-related defects, were identified in the section next to the ingate.

To analyse the distribution of the oxide-related defects in detail, each cross-section was subdivided into three different regions (Fig. 12): the upper side of the riser (UR), the lower side of the riser (LR) and the zone of the cylindrical test bar (TB). To obtain a statistical average of the distribution, the number of measured fields corresponding to the different SG values was evaluated and listed in Table 2 . The average SG was then calculated as weighted arithmetic mean in the different subdivided cross-sections.

The statistical analysis reported in Table 2 showed that the SG in the investigated sections was relatively low (lower than 1.7). These low values were not related to the presence of a few coarse defects; rather, they were linked to the formation of a large number of reduced-size defects. In detail, in the investigated crosssections there were $1104\left(\sim 1192 \mathrm{~mm}^{2}\right)$ grade 1 micrographs in comparison to 229 defect-free zones $\left(\sim 247 \mathrm{~mm}^{2}\right)$. Moreover, only 177 of the 2193 fields showed $A_{D}$ values between 0.8 and $1.5 \%$ (SG 3 or SG 4), and they were mostly located in the upper side of the riser. This is reasonable to expect from the casting geometry because the riser filled with material that has already flowed through the die cavity and the major part of entrained defects were accumulated in the "dead" riser.

However, the lack of old thick oxides confirmed the efficiency of the degassing treatment that was used during the experimental procedure.

To emphasise the entrainment of the oxide-related defects in the casting, filtering systems were not used in the present work. Although some studies [5, 26, 44] revealed how oxides that are micrometres thick are hardly trapped by millimetrepore-sized filters, these remain highly effective to reduce the velocity of the melt flow and to control over surface turbulence during the filling process $[5,45]$.

\subsection{Numerical simulation results}

To numerically investigate the entrainment of oxide inclusions, the filling velocity and the concentration of free surface defects, obtained from the simulation software, were considered. The first output was related to the action of the surface turbulence, which causes entrainment phenomena. The entrapment of bifilms and air/gas bubbles inside the bulk liquid is emphasised by a fluid velocity greater than the critical value for the generation of turbulence in $\mathrm{Al}$ alloys $(0.5 \mathrm{~m} / \mathrm{s})$ or the formation of vortexes during the filling phase [5]. 
Fig. 10 a FEG-SEM micrograph showing a large porosity contoured by a thin oxide layer indicated by arrows. EDS spectra refer to $\mathbf{b}$ the matrix surrounding the casting defect and $\mathbf{c}$ the oxiderelated defect
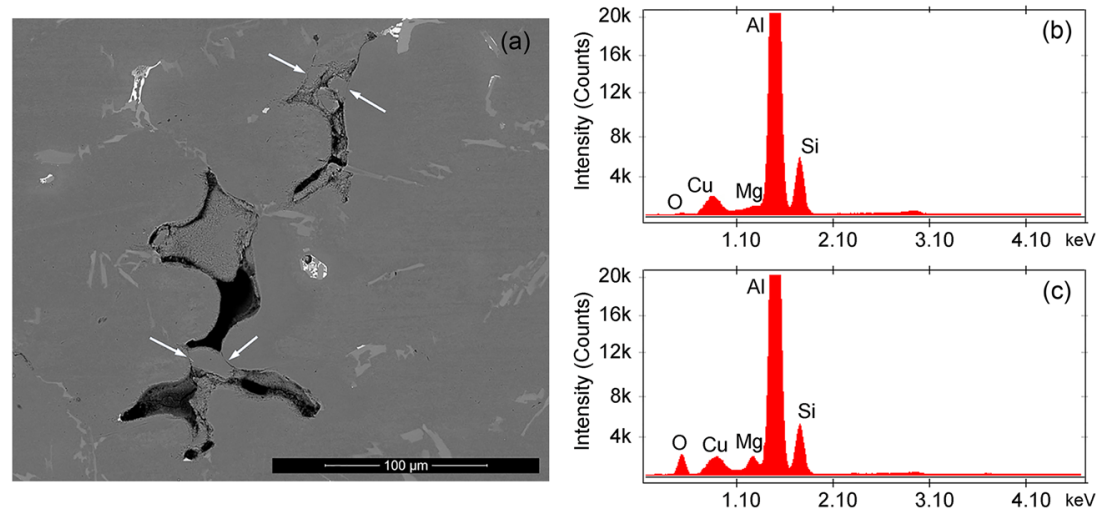

Figure 13 shows the variation in filling velocity over time from the beginning of the pouring phase at half width of the casting.

From the beginning of the filling phase, the fluid flow was turbulent. The metal velocity at the bottom of the pouring channel overcame the critical value for the generation of turbulence (Fig. 13a). The values remained high for the entire length of the bar cavity until the impact with the die surface at $0.40 \mathrm{~s}$ (see Fig. 13b). When the returning wave was generated and the metal began to flow inside the riser (Fig. 13c), the variation of cross-sectional area in the passage linking the bar cavity to the riser decreased the fluid velocity inside the riser. Figure $13 \mathrm{~d}$ and e show how the metal velocity decreased from $0.4-0.7 \mathrm{~m} / \mathrm{s}$ inside the bar cavity to $0.05-0.30 \mathrm{~m} / \mathrm{s}$ inside the riser.

As seen in Fig. 13d and e, the effects related to the absence of a filter (not used in the present work) are visible. At $1.65 \mathrm{~s}$, a vortex formed in the filter housing, which could become particularly damaging at the beginning of the filling of casting cavity. The combined action of air, which oxidises the molten metal, and the recirculation motions that entrap the oxide layers inside the bulk liquid, generally favours the formation and entrainment of bifilms. Furthermore, the fluid velocity downstream of the filter zone was still high because the absence of the filter did not facilitate the transition from a turbulent flow to a laminar regime flow.

At $5 \mathrm{~s}$ (Fig. 13f), although the die filling phase was completed, the fluid was not at rest; some metal fluctuations still existed, resulting in a non-stationary flow regime. These motions slowed as the time and solid fraction increased (Fig. 14) until $25 \mathrm{~s}$ from the beginning of the pouring phase when the flow velocity was equal to zero throughout the casting.

Figure 14 shows the distribution of the metal velocity and solid fraction in the investigated sections at $15 \mathrm{~s}$. The flow velocity was at rest in the test bar's cavity and in the lower zone of the riser, while slow recirculation motions were still detectable in the upper side of the casting. These vortexes promoted the backflow of metal from the free surface towards the inner region of the riser, as indicated by arrows in Fig. 14.

The second software output used to numerically investigate the entrainment phenomena was the concentration of free surface defects, whose distribution throughout the casting at the end of die filling is shown in Fig. 15. High values of defects could be observed in the zone of the riser that was in contact with the atmosphere, in particular in the regions of the upper side of the casting. The oxide concentration gradually decreased towards the inner zones of the casting; in particular, the cylindrical test bar appeared to be the soundest region. This distribution was depicted using the model described in Section 2. A scalar value, representative of the concentration of oxide defects, was accumulated in the cells where a surface of liquid metal was in contact with the atmosphere (free surface). The accumulation rate was constant over time, and the scalar could be transported from a cell to adjacent cells because of the flow movements or the convective motions.

In Fig. 15, the high accumulation of defects in the upper part of the open-type riser can be explained by the metal flow in the die cavity and the exposure time with air. Oxide defects were mainly accumulated at the top of the riser after that the liquid metal flowed through the whole die cavity. A longer flow path leads to a lower metal temperature and a greater oxidation time, which increases the probability of forming oxide skins, inclusions and cold laps.

Furthermore, the oxides that accumulated at the free surface of the riser could move towards the inner regions of the casting, especially at the farthest ends of the casting. This mechanism was due to the non-stationary flow regime at the end of the cavity filling phase. The presence of slow recirculation motions, indicated by arrows in Figs. 14 and 15, involved the redistribution of the oxide-related defects until $25 \mathrm{~s}$ from the beginning of the pouring phase when a steady-state condition was reached. In particular, along the investigated cross-sections, the decreasing gradient in the concentration of defects from the riser to the test bar was related to the vortexes illustrated in Fig. 14a, which promoted the oxide's movement from the upper part of the riser to the lower part of the riser. 


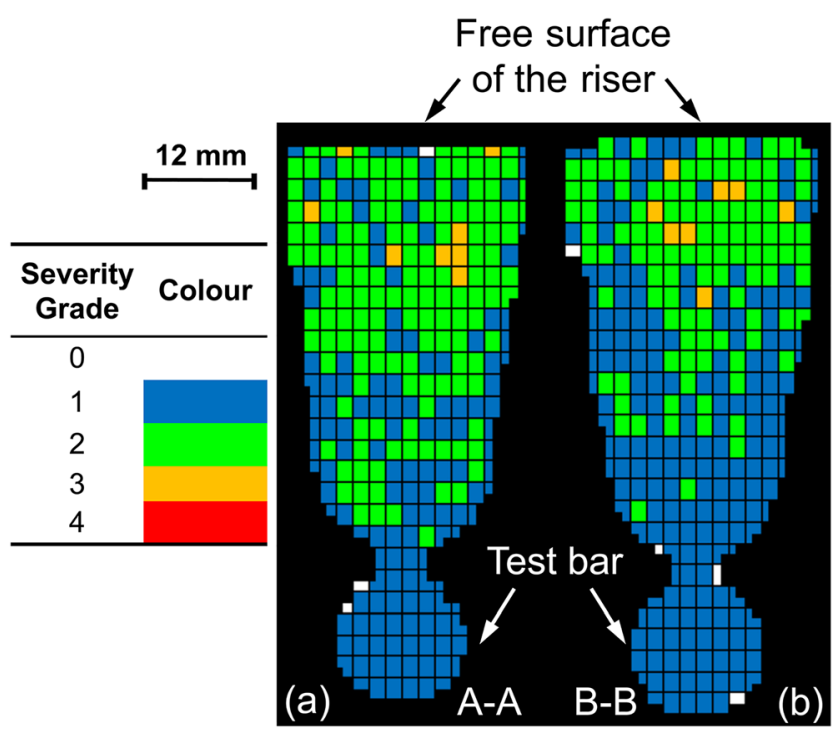

Fig. 11 Distribution of the SGs associated with the oxide-related defects in the cross-sections a close to (A-A) and $\mathbf{b}$ far from (B-B) the ingate after application of the $\mathrm{CNN}$ method (colour figure online)

\section{Discussion}

A reliable numerical prediction in the formation of oxiderelated defects can be achieved when both the fluid-dynamic behaviour of the metal and the cooling rate during solidification are properly modelled. Finally, an accurate model to predict the formation of oxide-related defects plays a key role. The lack of one of these aspects would result in a significant difference between the numerical distribution of entrainment defects and the experimental results.

In the present work, the numerical modelling of both metal flow and heat transfer was consistent with the experimental findings. The accurate modelling of fluid motions avoided erroneous predictions of turbulence on the free surface and entrainment phenomena, which could also result in inaccurate distribution and amount of defects. On the other hand, the proper modelling of the heat exchange between the molten metal and the die ensured that no premature or delayed solidification occurred. Furthermore, even though the die was here completely filled, the metal flow was not at rest, and the redistribution of defects continued until the solid fraction was high enough to prevent further fluid movements. Inaccurate modelling of the heat exchange would lead to longer or shorter solidification time, which would affect the final distribution of defects inside the casting.

Finally, an experimental mapping of oxide-related defects was carried out to provide the data necessary to validate the numerical models concerning the bifilms' entrainment. Figure 16 shows the comparison between the experimental distribution of oxide-related defects, in terms of SGs, and the numerical results referred to as the concentration of defects formed on the free surface. In both the numerical and experimental results, the bifilm concentration gradually increased

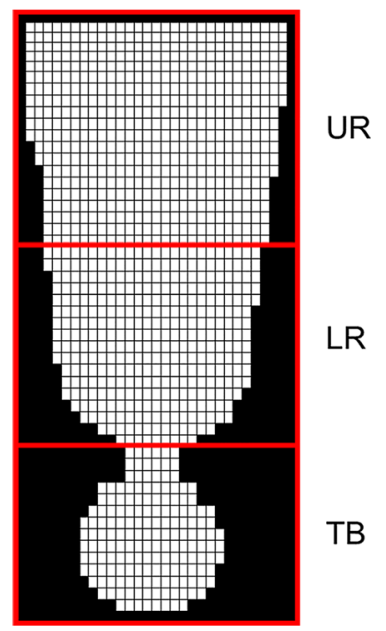

Fig. 12 Subdivided cross-section of the casting: upper side of the riser (UR), the lower side of the riser (LR) and the region of the test bar (TB)

from the zone of the test bar to the upper part of the riser, where the most damaged areas of the casting were detectable. This distribution of defects can be explained by studying the filling dynamics, which were found to be the same in the experimental and numerical results.

From the beginning of the filling phase, the metal flow regime was turbulent (Fig. 13a) due to the combined action of the pouring height and the short pouring time (approximately $3 \mathrm{~s}$ ). Indeed, the height of the pouring channel was $120 \mathrm{~mm}$, greater than the critical height of $12.5 \mathrm{~mm}$, which is generally the height from which an Al alloy can fall, accelerated by gravity, before reaching the critical velocity of $0.5 \mathrm{~m} / \mathrm{s}$ and generating a turbulent regime [5]. When the metal impacts the die, the turbulent flow could entrain the oxide layers or bubbles inside the liquid metal, immediately decreasing the quality of the molten metal from the beginning of the filling phase. This short but vulnerable period could play a key role in the quality of the final casting, especially when the melt is just entering the mould through the ingate.

Table 2 Statistical analysis of the oxide related-defects evaluated based on the number of measured fields corresponding to different SGs in the investigated subdivided cross-sections of the casting: upper (UR) and lower (LR) parts of the riser, and the zone of the test bar (TB)

\begin{tabular}{|c|c|c|c|c|c|c|c|}
\hline \multirow[t]{2}{*}{ Position } & & \multicolumn{6}{|c|}{ Severity grade } \\
\hline & & 0 & 1 & 2 & 3 & 4 & Mean \\
\hline \multirow[t]{3}{*}{ Section A-A } & TB & 44 & 131 & 4 & 0 & 0 & 0.8 \\
\hline & LR & 28 & 203 & 125 & 15 & 0 & 1.3 \\
\hline & UR & 19 & 174 & 224 & 74 & 5 & 1.7 \\
\hline \multirow[t]{3}{*}{ Section B-B } & TB & 39 & 131 & 9 & 1 & 0 & 0.8 \\
\hline & LR & 59 & 269 & 106 & 15 & 0 & 1.2 \\
\hline & UR & 40 & 196 & 215 & 61 & 6 & 1.6 \\
\hline \multicolumn{2}{|c|}{ Total number of fields } & 229 & 1104 & 683 & 166 & 11 & \\
\hline
\end{tabular}




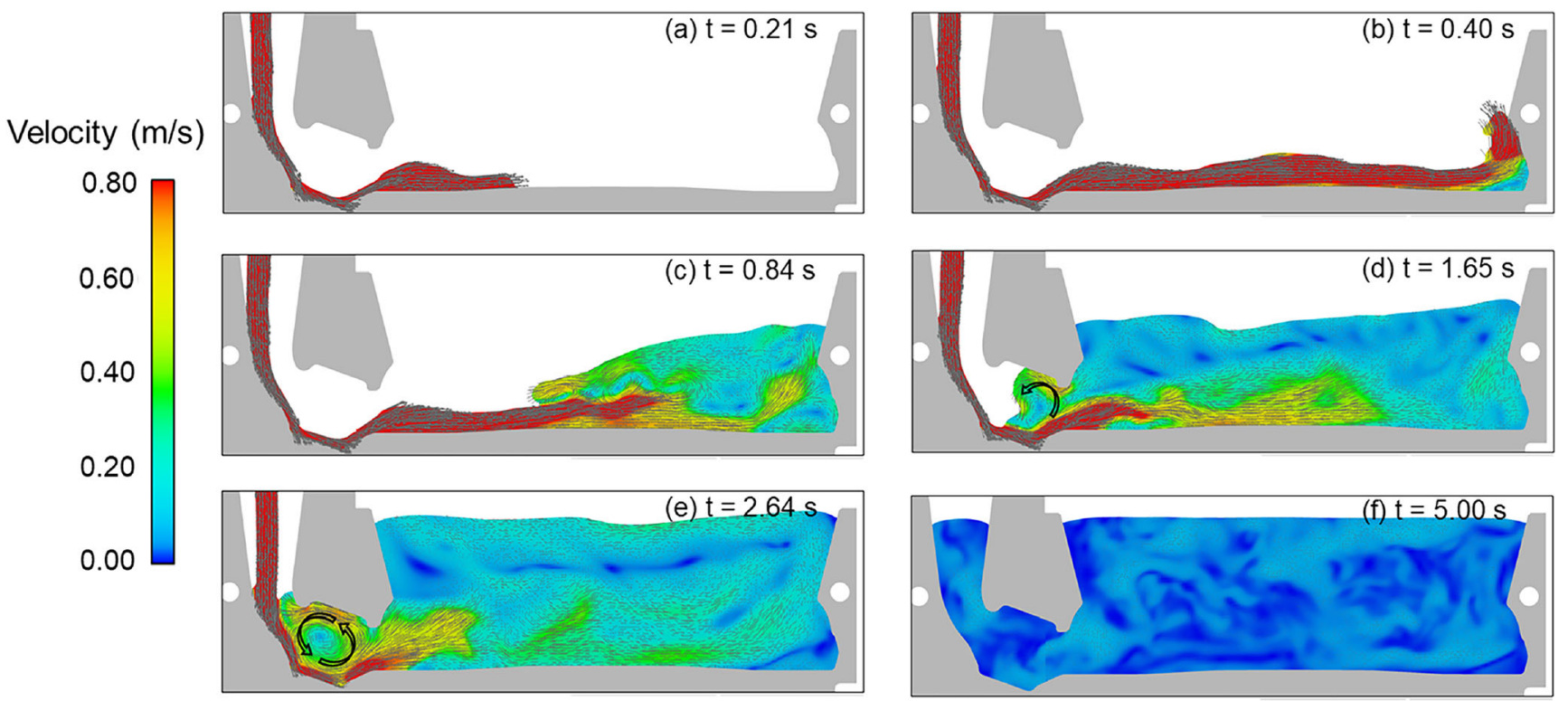

Fig. 13 Variation of the calculated melt velocity during the filling phase at half width of the casting. Velocity vectors and the formation of recirculation motions are illustrated, as indicated by the arrows; temporal references are calculated from the beginning of the pouring phase (colour figures online)

Moreover, the causes of the formation of the extended defects in the upper zone of the casting were recognised in both the simulated and empirical results. When the returning wave was formed (Figs. $6 \mathrm{~b}$ and $13 \mathrm{~b}$ ) and the two metal fronts, which flowed in opposite directions, were joined together (Fig. 7), a large oxidised surface could be easily entrained inside the bulk liquid. During the subsequent filling stages, the liquid metal pushed forward these entrainment defects and confined them in the upper part of the riser. In Fig. 16, the numerical concentration of the free surface defects in the region of the riser closest to the atmosphere was greater than $306 \cdot 10^{-5} \mathrm{~kg} / \mathrm{m}^{3}$, while the experimental area fraction covered by the oxiderelated defects mainly ranged from 0.2 to $1.6 \%$.
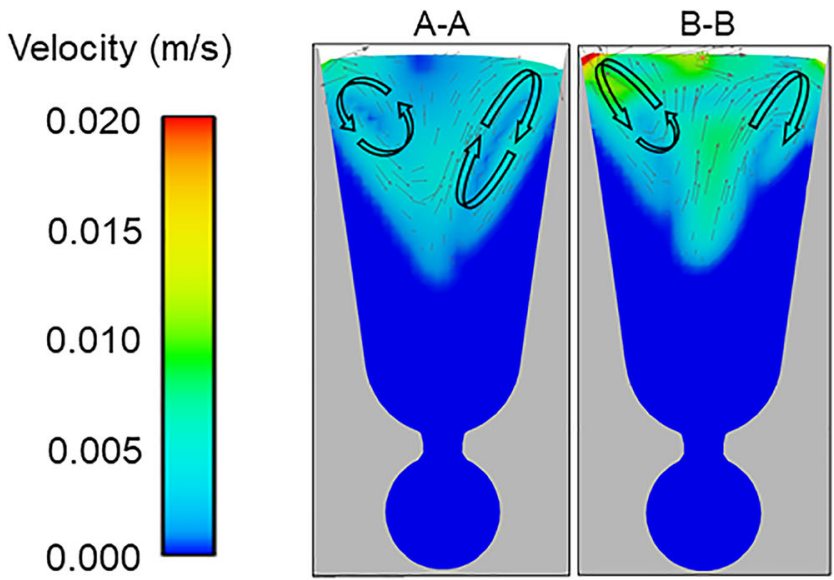

(a)

Fig. 14 Distribution of the calculated $\mathbf{a}$ melt velocity and $\mathbf{b}$ solid fraction in the investigated sections after $15 \mathrm{~s}$ from the beginning of the pouring phase; the velocity vectors are represented, and the recirculation zones are
In both the experimental and numerical results, the crosssection close to the ingate (section A-A) showed a slightly greater concentration of oxide-related defects in comparison to the section farthest from the ingate (section B-B). In particular, in the region immediately close to the riser's ingate, the calculated concentration of oxides was between $100 \cdot 10^{-5}$ and $306 \cdot 10^{-5} \mathrm{~kg} / \mathrm{m}^{3}$ in section A-A, while it ranged from $49 \cdot 10^{-5}$ to $196 \cdot 10^{-5} \mathrm{~kg} / \mathrm{m}^{3}$ in section B-B (Fig. 16b). According to the experimental results, the lower zone of the riser showed a mean SG of 1.2 and 1.3, respectively, in the areas furthest and closest to the ingate (Table 2).

This slight divergence between the investigated sections can be explained by the differences in the distances from the filter 
Free surface defects concentration $\left(\cdot 10^{-5} \mathrm{~kg} / \mathrm{m}^{3}\right)$
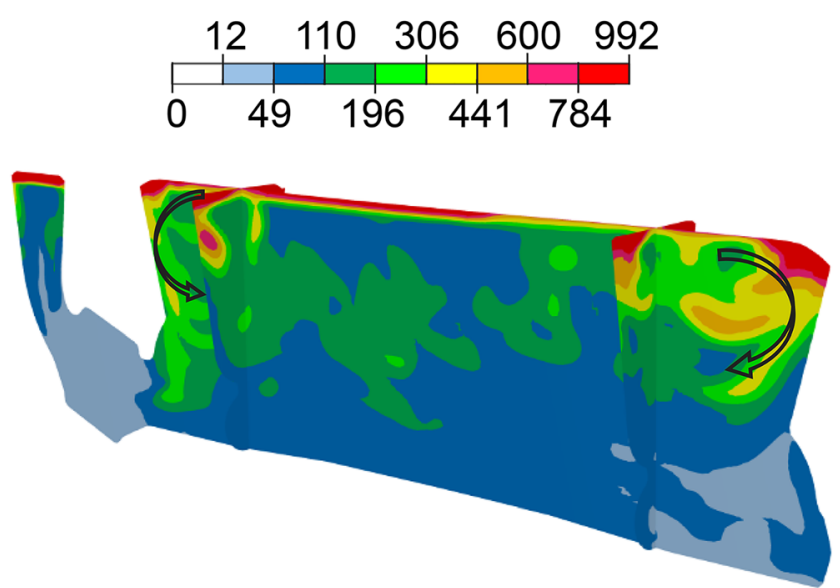

Fig. 15 Distribution of the calculated concentration of the free surface defects in the casting in the steady-state condition (from $25 \mathrm{~s}$ ). The recirculation motions, which promote the redistribution of the oxide-related defects from the surface to the inner zones of the riser, are indicated by arrows (colour figure online)

housing. From $5 \mathrm{~s}$ to $25 \mathrm{~s}$, although the die cavity was completely filled, the liquid $\mathrm{Al}$ was not at rest (Figs. $13 \mathrm{f}$ and 14), and the slow flow velocity was responsible for the non-homogeneous distribution of the bifilms inside the casting, especially in the riser.

In general, the numerical model used in this study successfully predicted the formation of oxides: the similarities in the distribution of the defects between the experimental and simulated results appear evident (Fig. 16). However, slight differences in the number of defects could be observed in the upper part of the riser. In the regions close to the free surface, the numerical accumulation of defects appeared to be slightly higher than the experimental findings. Two improvements could be implemented in the model to perfect the prediction: (1) the variation of the oxidation rate as a function of time and temperature and (2) the modelling of the strength effect and the buoyancy of the bifilm.

Regarding the first improvement, the numerical code accumulates defects on free surfaces at a constant rate, as a first approximation of the empirical oxidation rate, which is affected by time and temperature [6]. The pattern of the oxidation reaction over time can be described as an inverse logarithmic function up to about $350^{\circ} \mathrm{C}$, as a parabolic function from $350^{\circ} \mathrm{C}$ up to $450^{\circ} \mathrm{C}$, and as a linear or non-parabolic function at higher temperatures [46]. The approximation of the oxidation rate with a constant value over time implies to neglect the influence of the temperature. This can lead to overestimating the accumulation of defects on the free surfaces which are exposed to the atmosphere for long periods of time.

The second improvement concerns the modelling of the strength effect and the buoyancy of the bifilm, as well as its adhesion to the mould's walls; this was already proposed by Barkhudarov and Hirt [27]. In the current version, the model allows scalar values representing oxide defects to easily move from the free surface into the liquid metal under the action of weak fluid motions. On the contrary, the oxide surface skin formed over the liquid metal surface thickens over time, and it is hardly trapped inside the liquid metal, unless under the action of turbulent motion. Therefore, the redistribution of defects inside the liquid metal due to weak fluid motions is overestimated by the numerical simulation respect to the experimental observations.

The approximations of the cumulative scalar technique mainly affect the casting areas that have been in contact with the atmosphere for a long time after complete filling, such as the metal inside the pouring basin or open-type risers. Therefore, this technique appears particularly suitable for cast components with a mould geometry that minimise the contact between the molten metal and the atmosphere after complete filling, e.g. casting design with close-type risers.

Even though some improvements could be implemented to increase the prediction accuracy of entrainment defects, these changes would significantly increase the calculation time
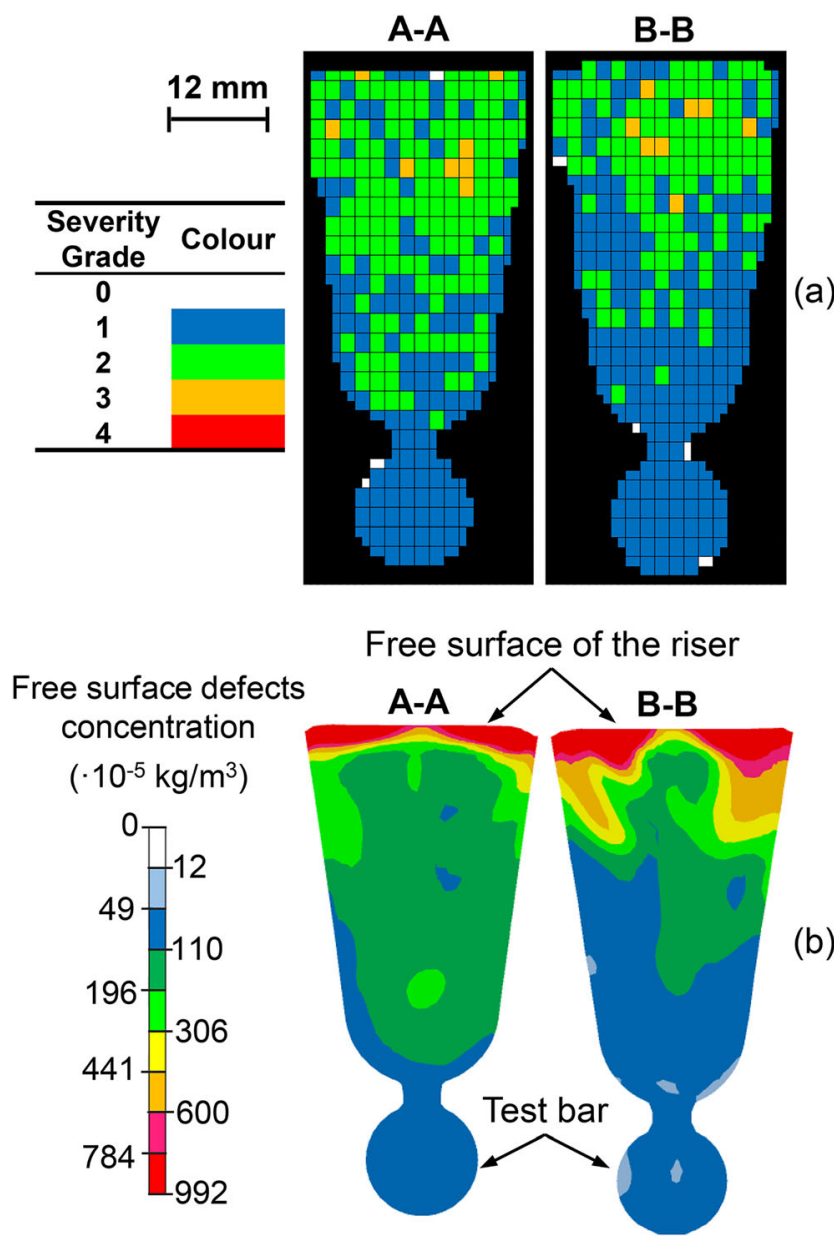

(b)

Fig. 16 Comparison between a the experimental distribution of the SGs related to the oxide inclusions and $\mathbf{b}$ the numerical output concerning the formation of the defects on the free surface in the steady-state condition (from $25 \mathrm{~s}$ ). The cross-sections near to (A-A) and far from (B-B) the ingate are shown (colour figures online) 
during numerical simulation, which is already high for large and complex components.

The capacity to reliably foresee the formation, distribution and amount of entrainment defects in a short calculation time is a key issue to obtain high-integrity components with reduced time for the design and engineering phases. Further improvements to expand the use scenarios of the present numerical model concern the implementation of optimisation algorithms, which allow the estimation of the optimum values of the variables involved in the casting process, e.g. metal and die temperatures, and filling velocity [47]. These algorithms would allow to easily select the casting parameters in order to minimise the formation of entrainment and to increase the quality of casting parts.

\section{Conclusions}

In this study, both numerical and experimental investigations on the formation and distribution of oxide-related defects in AlSi7Cu0.5Mg cast alloy were conducted. A free surface tracking model was used to numerically analyse the position and growth time of the oxide film. A cumulative scalar technique was implemented in the numerical code to predict the formation of oxides on the free surface. The following conclusions can be drawn.

- The free surface tracking algorithm is accurate in the modelling of oxide surface motion. In the filling stage, a good correspondence was found between the numerical and experimental results regarding the position of the fluid front and the filling level of the die.

- The numerical prediction of the formation of oxide-related defects is consistent with the experimental results. A clear similarity was found between the severity grade mapping caused by the entrainment of the bifilms and the numerical distribution of oxides formed on the free surface.

- According to the cumulative scalar technique, the modelling of the oxidation rate and the properties of the bifilms is neglected. In comparison to the experimental findings, these features led to a slightly higher accumulation of defects in the regions close to the free surface of the casting.

Acknowledgements The authors would like to thank Prof. M. Tiryakioğlu for the stimulating discussions.

Author contribution Giulia Scampone: conceptualization, investigation, validation and writing - original draft. Raul Pirovano and Stefano Mascetti: numerical simulation (software). Giulio Timelli: conceptualization, supervision and writing - review and editing.

Funding Open access funding provided by Università degli Studi di Padova within the CRUI-CARE Agreement. This work was developed with the financial support of the Fondazione Cassa di Risparmio di Padova e Rovigo (CariPaRo).

Data availability Not applicable

Code availability Not applicable

\section{Declarations}

Ethics approval This article does not contain any studies with human participants or animals performed by any of the authors.

Consent to participate This article does not contain any studies with human participants or animals performed by any of the authors.

Consent for publication This article does not contain any studies with human participants or animals performed by any of the authors.

Competing interest The authors Scampone and Timelli declare that they have no financial interests. The authors Pirovano and Mascetti are employees of XC Engineering S.r.1, an engineering company representing several CAE software.

Open Access This article is licensed under a Creative Commons Attribution 4.0 International License, which permits use, sharing, adaptation, distribution and reproduction in any medium or format, as long as you give appropriate credit to the original author(s) and the source, provide a link to the Creative Commons licence, and indicate if changes were made. The images or other third party material in this article are included in the article's Creative Commons licence, unless indicated otherwise in a credit line to the material. If material is not included in the article's Creative Commons licence and your intended use is not permitted by statutory regulation or exceeds the permitted use, you will need to obtain permission directly from the copyright holder. To view a copy of this licence, visit http://creativecommons.org/licenses/by/4.0/.

\section{References}

1. Jiang W, Fan Z, Liu D, Wu H (2013) Influence of gas flowrate on filling ability and internal quality of A356 aluminum alloy castings fabricated using the expendable pattern shell casting with vacuum and low pressure. Int J Adv Manuf Technol 67:2459-2468. https:// doi.org/10.1007/s00170-012-4663-5

2. Dispinar D, Campbell J (2007) Effect of casting conditions on aluminium metal quality. J Mater Process Technol 182:405-410. https://doi.org/10.1016/jjmatprotec200608021

3. Tiryakioğlu M, Yousefian P, Eason PD (2018) Quantification of entrainment damage in A356 aluminum alloy castings. Metall Mater Trans A 49:5815-5822. https://doi.org/10.1007/s11661-018-4865-z

4. Sarfraz S, Jahanzaib M, Wasim A, Hussain S, Aziz H (2017) Investigating the effects of as-casted and in situ heat-treated squeeze casting of Al-35\% Cu alloy. Int J Adv Manuf Technol 89:3547-3561. https://doi.org/10.1007/s00170-016-9350-5

5. Campell J (2011) Complete casting handbook: metal casting processes, metallurgy, techniques and design, 2nd edn. ButterworthHeinemannpp, Oxford-Waltham pp 11-13, 17-50, 67-72, 607-613, 776, 833-852, 899-901

6. Birks N, Meier GH, Pettit FS (2006) Introduction to the high temperature oxidation of metals, 2nd edn. Cambridge University Press, Cambridge, p 49-66, 69-73, 82,83. https://doi.org/10.1017/ CBO9781139163903

7. Campell J (2019) Update on bifilms - the fundamental defect in metals. In: Tiryakioğlu M, Griffiths W, Jolly M (eds) Shape casting: 7th International Symposium 2019 The Minerals, Metals \& 
Materials Serie. Springer, Cham, pp 3-5. https://doi.org/10.1007/ 978-3-030-06034-3 1

8. Uludağ M, Çetin R, Dispinar D, Tiryakioğlu M (2018) The effects of degassing, grain refinement \& Sr-addition on melt quality-hot tear sensitivity relationships in cast A380 aluminum alloy. Eng Fail Anal 90:90-102. https://doi.org/10.1016/jengfailanal201803025

9. Bagherpoor-Torghabe H, Niroumand B, Karbasi M (2014) On the effect of gating system type on occurrence of hot tears in Al-4 wt\% $\mathrm{Cu}$ castings. Int J Adv Manuf Technol 75:677-685. https://doi.org/ 10.1007/s00170-014-6172-1

10. El-Sayed MA, Hassanin H, Essa K (2016) Bifilm defects and porosity in Al cast alloys. Int J Adv Manuf Technol 86:1173-1179. https://doi.org/10.1007/s00170-015-8240-6

11. Yousefian P, Tiryakioğlu M (2018) Pore formation during solidification of aluminum: reconciliation of experimental observations, modeling assumptions, and classical nucleation theory. Metall Mater Trans A 49:563-575. https://doi.org/10.1007/s11661-017-4438-6

12. Uludağ M, Çetin R, Gemi L, Dispinar D (2018) Change in porosity of A356 by holding time and its effect on mechanical properties. J Mater Eng Perform 27:5141-5151. https://doi.org/10.1007/ s11665-018-3534-0

13. Akaberi N, Taghiabadi R, Razaghian A (2017) Effect of bifilm oxides on the dry sliding wear behavior of Fe-rich Al-Si alloys. J Tribol 139:1-10. https://doi.org/10.1115/1.4035340

14. El-Sayed MA, Salem HA, Kandeil AY et al (2011) Effect of holding time before solidification on double-oxide film defects and mechanical properties of aluminum alloys. Metall Mater Trans B Process Metall Mater Process Sci 42:1104-1109. https://doi.org/ 10.1007/s11663-011-9571-9

15. Dispinar D, Akhtar S, Nordmark A, Syvertsen F, Di Sabatino M, Arnberg L (2012) Correlation between mechanical properties and porosity distribution of A356 in gravity die casting and low pressure die casting. Adv Mater Res 445:283-288. https://doi.org/10. 4028/wwwscientificnet/AMR445283

16. Sun J, Le Q, Fu L, Bai J, Tretter J, Herbold K, Huo H (2019) Gas entrainment behavior of aluminum alloy engine crankcases during the low-pressure-die-casting process. J Mater Process Technol 266: 274-282. https://doi.org/10.1016/jjmatprotec201811016

17. Timelli G, Caliari D, Rakhmonov J (2016) Influence of process parameters and $\mathrm{Sr}$ addition on the microstructure and casting defects of LPDC A356 alloy for engine blocks. J Mater Sci Technol 32:515-523. https://doi.org/10.1016/jjmst201603010

18. Gyarmati G, Fegyverneki G, Tokár M, Mende T (2021) The effects of rotary degassing treatments on the melt quality of an Al-Si casting alloy. Int J Met 15:141-151. https://doi.org/10.1007/s40962-020-00428-Z

19. Reilly C, Green NR, Jolly MR (2013) The present state of modeling entrainment defects in the shape casting process. Appl Math Model 37:611-628. https://doi.org/10.1016/japm201204032

20. Yue Y, Griffiths WD, Fife JL, Green NR (2012) In situ characterisation of entrainment defects in liquid $\mathrm{Al}-\mathrm{Si}-\mathrm{Mg}$ alloy. 1st International Conference on 3D Materials Science 2012, 3DMS 2012 131-136. https://doi.org/10.1007/978-3-319-48762-5 20

21. Song H, Zhang L, Cao F, Gu X, Sun J (2021) Oxide bifilm defects in aluminum alloy castings. Mater Lett 285:129089. https://doi.org/ 10.1016/j.matlet.2020.129089

22. Chen Q, Griffiths WD (2021) Modification of double oxide film defects with the addition of Mo to An Al-Si-Mg alloy. Metall Mater Trans B Process Metall Mater Process Sci 52:502-516. https://doi. org/10.1007/s11663-020-02038-w

23. Das P, Bhuniya B, Samanta SK, Dutta P (2019) Studies on die filling of A356 Al alloy and development of a steering knuckle component using rheo pressure die casting system. J Mater Process Technol 271:293-311. https://doi.org/10.1016/ jjmatprotec201904014
24. Cao L, Liao D, Sun F, Chen T (2018) Numerical simulation of coldlap defects during casting filling process. Int $\mathrm{J}$ Adv Manuf Technol 97:2419-2430. https://doi.org/10.1007/s00170-018-2012-z

25. Verran GO, Mendes RPK, Rossi MA (2006) Influence of injection

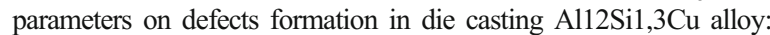
experimental results and numeric simulation. J Mater Process Technol 179:190-195. https://doi.org/10.1016/jimatprotec200603089

26. Ardekhani A, Raiszadeh R (2012) Removal of double oxide film defects by ceramic foam filters. J Mater Eng Perform 21:13521362. https://doi.org/10.1007/s11665-011-9991-3

27. Barkhudarov MR, Hirt CW (1998) Tracking defects, In: 1st International Aluminium Casting Technology Symposium, October 12-15 1998, Rosemont, IL published by ASM, Metals Park, OH

28. EN 1706:2020, Aluminium and aluminium alloys - castings chemical composition and mechanical properties

29. CEN/TR 16748:2014, Aluminium and aluminium alloys - mechanical potential of Al-Si alloys for high pressure, low pressure and gravity die casting

30. FOSECO (ed) Dycote ${ }^{\circledR}$ - Manual-coatings for non-ferrous metal die-casting, 1st edn. Foseco Int Ltd, Tamworth, U.K., pp 1-28

31. Vander Voort GF (1999) Metallography - Principles and practice, 1st edn. McGraw-Hill, New York, p 610

32. Vandersluis E, Ravindran C (2017) Comparison of measurement methods for secondary dendrite arm spacing. Metallogr Microstruct Anal 6:89-94. https://doi.org/10.1007/s13632-016-0331-8

33. Dertat A (2017) Applied deep learning - part 4: convolutional neural networks. Towards Data Science. https://towardsdatascience. com/applied-deep-learning-part-4-convolutional-neural-networks584bc134c1e2. Accessed 20 December 2020

34. FLOW-3D® Version 12.0.2 Users manual (2020) FLOW-3D [computer software] Santa Fe, Flow Science, Inc

35. M.R. Barkdudarov, C.W. Hirt (1995) Casting Simulation: Mold Filling and Solidification - Benchmark Calculations Using FLOW3D, In: Modeling of Casting, Welding and Advanced Solidification Processes VII: proceedings of the Seventh Conference in a Series on Modeling, Casting and Welding Processes, September 10-15 1995, London, England, published by The Minerals, Metals \& Materials Society, Warrendale, PA, USA, pp 935-946

36. Hirt CW, Nichols BD (1981) Volume of fluid (VOF) method for the dynamics of free boundaries. J Comput Phys 39:201-225. https://doi.org/10.1016/0021-9991(81)90145-5

37. Lewis RW, Ransing RS (1998) Correlation to describe interfacial heat transfer during solidification simulation and its use in the optimal feeding design of castings. Metall Mater Trans B Process Metall Mater Process Sci 29:437-448. https://doi.org/10.1007/ s11663-998-0122-y

38. Lewis RW, Ransing RS (2000) Optimal design of interfacial heat transfer coefficients via a thermal stress model. Finite Elem Anal Des 34:193-209. https://doi.org/10.1016/S0168-874X(99)00038-4

39. Hirt CW, Barkhudarov MR (2013) Void regions and bubble models in FLOW-3D Flow Science Report 01-13, Flow Science, Inc, Santa Fe. https://www.flow3d.co.kr/wp-content/uploads/FSR 01-13 Void-Regions-and-Bubble-Models-in-FLOW-3D.pdf. Accessed 10 November 2020

40. Wilcox DC (2008) Formulation of the k- $\omega$ turbulence model revisited. AIAA J 46:2823-2838. https://doi.org/10.2514/136541

41. Hirt CW (2014) Surface tension modelling, Flow Science Report 01-14, Flow Science, Inc, Santa Fe. https://flow3d.co.kr/wpcontent/uploads/FSR_01-14_Surface-Tension-Modelling.pdf. Accessed 10 November 2020

42. Wang QG, Càceres CH (1997) Mg effects on the eutectic structure and tensile properties of Al-Si-Mg alloys. Mater Sci Forum 242: 159-164. https://doi.org/10.4028/wwwscientificnet/MSF242159

43. Brůna M, Bolibruchová D, Pastirčák R (2017) Numerical simulation of porosity for Al based alloys. Procedia Eng 177:488-495. https://doi.org/10.1016/jproeng201702250 
44. Hsu FY, Li CL (2015) Runner systems containing ceramic foam filters quantified by "area normalized" bifilm index map. Int J Met 9:23-35. https://doi.org/10.1007/BF03355620

45. Švecová I, Tillová E, Kuchariková L (2020) Improving the quality of Al-Si castings by using ceramic filters. Production Engineering Archives 26:19-24. https://doi.org/10.30657/pea20202605

46. Bonner S (2015) A microstructural and kinetic study of molten aluminium oxidation in relation to dross formation. Dissertation, University of Queensland. https://doi.org/10.14264/uq12015897
47. Papanikolaou M, Saxena P, Salonitis K, Jolly MR (2020) Optimisation of the filling process in counter-gravity casting. In: IOP Conf. Series: Materials Science and Engineering 861: 012031 https://doi.org/10.1088/1757-899X/861/1/012031

Publisher's note Springer Nature remains neutral with regard to jurisdictional claims in published maps and institutional affiliations. 